\title{
Ice ridge keel geometry and shape derived from one year of upward looking sonar data in the Fram Strait
}

\author{
Ole-Christian Ekeberg ${ }^{\mathrm{a}, \mathrm{b}, *}$, Knut Høyland ${ }^{\mathrm{a}, \mathrm{c},}$, Edmond Hansen ${ }^{\text {d,e, }}$ \\ ${ }^{a}$ Norwegian University of Science and Technology (NTNU), Department of Civil and Transport Engineering, Hфyskoleringen $7 a, N$-7491 \\ Trondheim, Norway \\ ${ }^{b}$ DNV GL, N-1363 Høvik, Norway \\ ${ }^{c}$ Sustainable Arctic Marine and Coastal Technology (SAMCoT), Centre for Research-based Innovation (CRI), Norwegian University of Science \\ and Technology, Trondheim, Norway \\ ${ }^{d}$ Norwegian Polar Institute, N-9296 Troms $\phi$, Norway \\ ${ }^{e}$ Now at Multiconsult, $N$-9296 Troms $\phi$, Norway
}

\begin{abstract}
Ice ridge keel geometry was studied by analyzing one year of upward looking sonar data collected in the Transpolar drift stream at $79^{\circ} \mathrm{N}, 6.5^{\circ} \mathrm{W}$ in $2008 / 2009$. Ridges were identified using the Rayleigh criterion with a threshold value of $2.5 \mathrm{~m}$ and a minimum draft of $5 \mathrm{~m}$. The keel shape was studied after the identification of ridges from temporal data. On average ridge keels were symmetric both with respect to the centroid of the keel and the keel crest location. By quantifying the ratio between observed keel area and the keel area of an assumed triangular keel shape (often assumed for first year ridges) we observed that in $79 \%$ of the cases the ridge cross sectional area would be underestimated by a triangular keel shape. Because keel loads on ships and structures increase with keel draft and keel area it is important that an assumed keel shape maintains the observed keel area. Thus we suggest that a better generalization of the shape of first year ridges is a trapezoidal keel shape rather than triangular. Based on the observations the mean trapezoidal keel, representing both first year ridges and old ridges, has a keel bottom-width which on average is $17 \%$ of the keel width. For the deepest keels $(>15 \mathrm{~m})$ the mean keel bottom width was $12 \%$ of the keel width. The mean keel draft was $7.3 \mathrm{~m}$ and the deepest ridge was $25 \mathrm{~m}$. The temporal data was converted to spatial data based on an ice drift speed estimate which assumed free drift. From the spatial data we found that the mean keel width was $28 \mathrm{~m}$ and the mean keel cross sectional area was $164 \mathrm{~m}^{2}$.
\end{abstract}

Keywords: Ice ridge keel geometry, Symmetry, Upward looking sonar, Fram Strait, Keel shape

\section{Introduction}

Ice ridges often give the governing design action for both pipelines and offshore structures in ice covered waters. Ice ridges are formed from ice floes as they break in compression and shear due to environmental forces. This breaking result in a pile of ice blocks which with time freeze together and forms an ice ridge which has two distinct layers: a keel below the waterline and a sail above. At the waterline a completely frozen layer forms which is called the consolidated layer. The consolidation process progresses with time and when an ice ridge survives a summer's melt it is assumed to be close to fully consolidated. During its first winter an ice

\footnotetext{
*Tel: + 4797682644

Email address: 0le.Christian.Ekeberg@ntnu.no ()
}

ridge is called a first-year (FY) ridge. Ridges which survive one or more summer are second-year- and multiyear-ridges respectively and have the collective term old ridges (World Meteorological Organization, 1989; ISO19906, 2010).

Ridge keel load models vary in which geometric parameter that represents the the geometry of the ridge keels. Most common is the use of keel draft as the only input, which is the case in the analytical models by (Prodanovic, 1979; Dolgopolov et al., 1975; Mellor, 1980; Croasdale et al., 1994) while the cross sectional area of the ridge keel is the only input to the analytical models by (Prodanovic, 1981; Croasdale, 1980). More advanced numerical models by (Heinonen, 2004; Serré, 2011) could employ any ridge shape. A less advanced numerical model was developed by Kärnä et al. (2001) who included both the failure modes suggested by Dol- 
gopolov et al. (1975) and Croasdale (1980). This model assumes a trapezoidal ridge. Kärnä et al. (2001) suggest that if certain simplifications are included in the model it could be used in probabilistic analysis.

The geometry of both the sail and the keel of an ice ridge can only be obtained by profiling an ice ridge by drilling. Discrete measurements of ridges, such as by drilling, only amount to about 300-400 ridges during the past 40 years (Strub-Klein and Sudom, 2012). Based on a collection of such ridges Timco and Burden (1997), and later Strub-Klein and Sudom (2012), suggest some parametric relationships between different geometric parameters for the sail and the keel. The findings of Timco and Burden (1997) also form the basis of the suggested relationships in ISO19906 (2010).

Discrete measurements of ridges assumes a length and width of the ridge keel and the keel geometry is measured in the section which visually most clearly fits this assumption. While many assume that ridges are straight linear features Bowen and Topham (1996) did show that a portion of the ridge keels are not in the linear segments but in more complex corner structures.

An alternative way of sampling information about ice ridge geometry is the use of continuous scanning methods. These are limited to measurements of either the top surface or the bottom surface of the ice. The ice bottom surface has traditionally been measured using upward looking sonars but recently the bottom surface has also been mapped in three dimensions using a multi-beam sonar (Doble et al., 2009; Wadhams and Toberg, 2012). Upward looking sonars (ULS) have been in use since the beginning of the 1960s on submarines (Hibler et al., 1972) while bottom mounted sonars started to be developed in the late 1970s (Pilkington and Wright, 1991; Melling et al., 1995).

A ULS measures ice thickness by sending a sound pulse toward the ice surface and measuring the time it takes to return. Then, the distance to the ice surface is calculated by the speed of sound in the water above the ULS. Further, the distance to sea level is derived from pressure measurements at the ULS and the pressure at sea level. Ice draft is then the difference in distance between the water and the ice surface. The final product from a ULS is a time series of ice draft. A conversion to a spatial series is possible if the ice drift speed is recorded by an Acoustic Doppler Current Profiler (ADCP) (Melling et al., 1995) or as in the case of a submarine knowing the speed of the vessel. Melling et al. (1995) provide a comprehensive description of the most common moored ULS which is the Ice Profiler Sonar (IPS).

The main interest of those who have analyzed ULS data have been to monitor and estimate changes in the ice thickness probability density function and observe the ice export out of the Fram Strait (Vinje et al., 1998; Rothrock et al., 1999; Wadhams and Davis, 2000; Melling et al., 2005). Identification and analysis of ridges from ULS data have largely been reported in Davis and Wadhams (1995); Melling and Riedel (1995, 1996); Wadhams (2000); Obert and Brown (2011); Marcellus et al. (2011).

Since 1990, the Norwegian Polar Institute has measured ice drafts along $79^{\circ} \mathrm{N}$ in the Fram Strait using bottom mounted upward looking sonars (Vinje et al., 1998; Hansen et al., 2013). The Fram Strait is the output end of the Transpolar Drift, which continuously delivers Arctic sea ice through the strait. Hence the location naturally lends itself to monitoring Arctic sea ice thicknesses. In 2006, an IPS replaced the CMR ES-300 (described by Strass, 1998) which had been in use since 1990. The IPS measured the draft every 2 seconds in contrast to the CMR ES-300 which typically sampled every 4 minutes.

\section{Data collection and processing}

From September 2008 to September 2009 an IPS, denoted F14, was recording the ice draft close to the edge of the Greenland continental shelf at $78^{\circ} 49^{\circ} \mathrm{N}, 6^{\circ} 26^{\circ} \mathrm{W}$ (Fig. 1). Water depth was $280 \mathrm{~m}$ and the instrument depth was on average $46 \mathrm{~m}$. The mooring was deployed and retrieved during an annual scientific cruise to the Fram Strait in August/September by the Norwegian Polar Institute. This IPS measured the ice draft every 2 seconds and tilt and pressure every 120 seconds. It had a $1.8^{\circ}$ beamwidth which gives a nominal footprint at the water surface of $1.5 \mathrm{~m}$. The closest draft within the footprint was recorded as long its returning echo had sufficient strength and duration. Melling et al. (1995) and Rodrigues (2011) discuss effects that originate from this 'footprint widening'. Conversion from raw data into a time series of drafts follows the methodology described in Melling et al. (1995). The accuracy of an individual draft observation was estimated to about $\pm 5 \mathrm{~cm}$ by Melling and Riedel (1995). The 2008/2009 season ice was present year-round with most ridges from October to August.

\subsection{Time series - spatial series}

The geometry of an ice ridge keel could be studied both from temporal data and spatial data. Many parameters do not require a conversion to spatial data and are therefore derived directly from the time series. These 


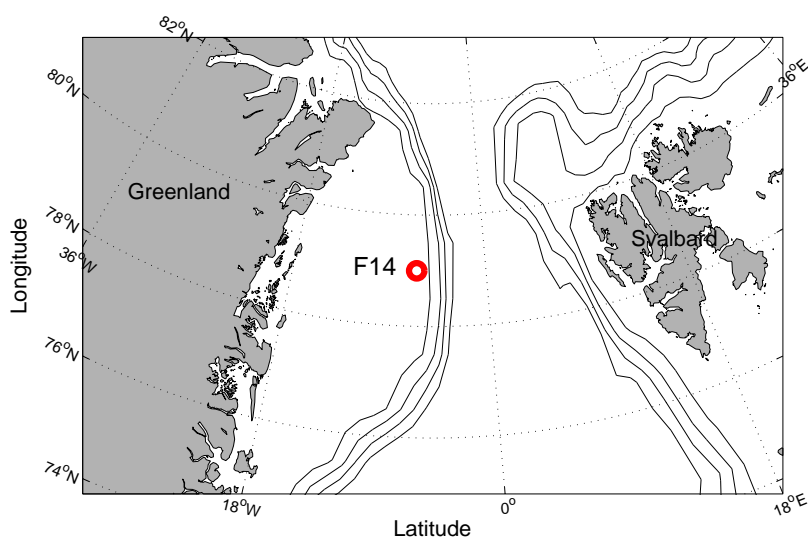

Figure 1: Location of ice draft measurements, depth contours every $500 \mathrm{~m}$.

were the keel area coefficient, the location of the deepest point of the keel, the centroid of the keel and the keel draft. Parameters that were derived from spatial data are the keel width and the keel area. The ridge keels were identified from the temporal data but ridges would have identical starting and ending points regardless if they were identified from temporal or spatial data as long as smoothing were done prior to a conversion like in this study.

\subsection{Spatial parameters}

\subsubsection{Ridge keel geometry}

The geometry of a ridge is shown in Fig. 2. The start and end of the keel is labeled $P_{1}$ and $P_{4}$ and is either the point where the ice draft $\left(h_{i}\right)$ crosses the threshold or the point shared by two keels which then is the lowest draft between the two keels. The keel width $\left(w_{k}\right)$ and total keel area $\left(A_{k}\right)$ are defined by eqs. 1 and 2 . The dimension in the $\mathrm{x}$-direction is meter but could also be seconds (see section 2.3).

$$
\begin{gathered}
w_{k}=x\left(P_{4}\right)-x\left(P_{1}\right) \\
A_{k}=\frac{1}{2} \sum_{j=1}^{N}\left(x_{j+1}-x_{j}\right) \cdot\left(h_{i}\left(x_{j+1}\right)+h_{i}\left(x_{j}\right)\right)
\end{gathered}
$$

where $\mathrm{N}+1$ is the number of observations from and including $P_{1}$ to and including $P_{4}$.

As long as the ridge length and width of the keel can be defined the ridge orientation is given by $\alpha$ (Fig. 3) which is the angle between the keel crest and the $\mathrm{x}$-axis. The keel crest is the line which the deepest point in the

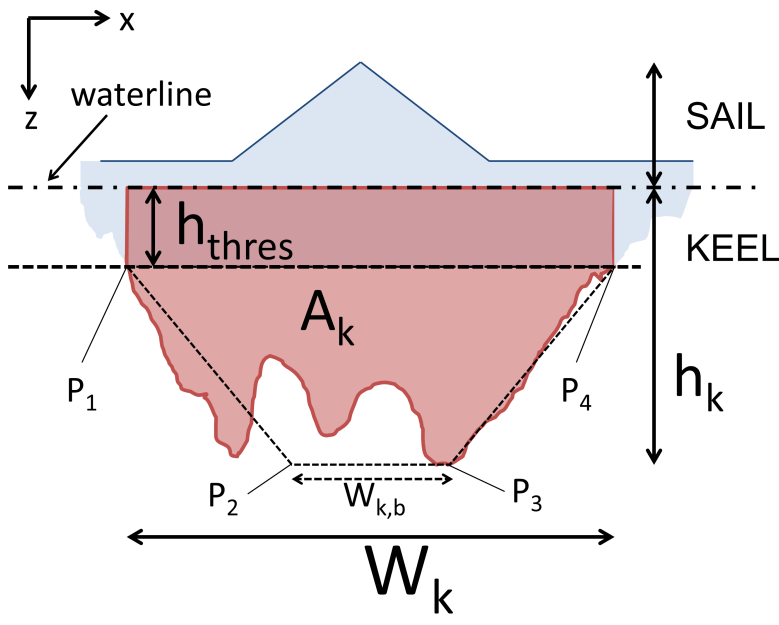

Figure 2: An example of an ice ridge cross section with the threshold value $\left(h_{\text {thres }}\right)$, keel draft $\left(h_{k}\right)$, keel width $\left(w_{k}\right)$ and the keel area $\left(A_{k} /\right.$ dark red) as defined.

keel cross section $\left(h_{k}\right)$ makes in the $\mathrm{x}-\mathrm{y}$ direction and is straight when the keel cross sectional shape remain unchanged in the $\mathrm{x}-\mathrm{z}$ plane. If the orientation is $90^{\circ}$ the observed keel width (by the ULS) is what normally is considered the keel width and is in Fig. 3 referred to as the true keel width $\left(w_{k, t r u e}\right)$. When the ridge orientation deviate from $90^{\circ}$ the keel width (or area) is greater than $w_{k, \text { true }}$ and is referred to with subscript $o b s$ in Fig. 3. Then $w_{k, \text { true }}$ could be found from eq. 3 . In the current study the ridge orientation was unknown and we present $w_{k, o b s}$ as $w_{k}$.

$$
w_{k, \text { true }}=w_{k, o b s} \cdot \sin (\alpha)
$$

\subsection{Temporal parameters}

\subsubsection{Ice ridge identification criterion}

Ridges were identified using the Rayleigh criterion with a threshold value of $2.5 \mathrm{~m}$ and a minimum draft of $5 \mathrm{~m}$ (Wadhams and Horne, 1980). This choice was done to be in line with previous work such as Wadhams et al. (2011); Wadhams and Davis (2000); Melling and Riedel (1996). The Rayleigh criterion defines an individual ice ridge when the ice thickness on each side of a local maxima descends at least halfway toward $h_{\text {thres }}$ (Fig. 2). The threshold value $\left(h_{\text {thres }}\right)$ was set to $2.5 \mathrm{~m}$ which was greater than the level ice thickness in this location (Hansen et al., 2013). A sufficiently high threshold value should be used to avoid that level ice is defined to be within ridges. A minimum draft of $5 \mathrm{~m}$ excluded all ridges with keel draft less than $5 \mathrm{~m}$ deep and ensured 


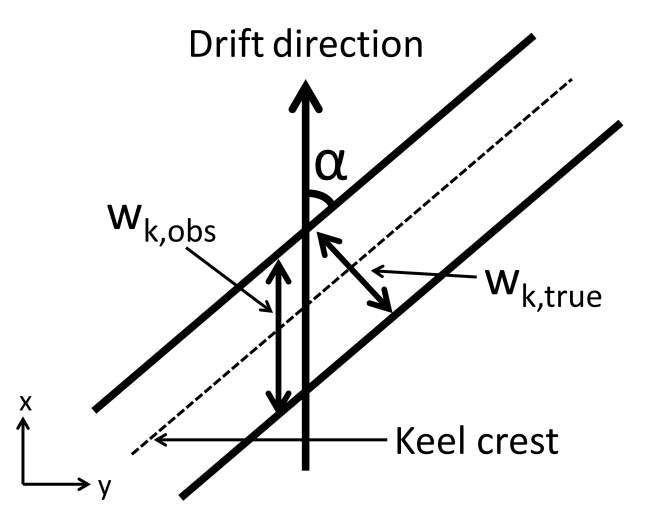

Figure 3: An idealized ridge where the keel cross section is constant along the keel crest. The keel start $\left(P_{1}\right)$ and end $\left(P_{4}\right)$ are the solid lines while the deepest point of the ridge is the dotted line referred to as the keel crest. $\alpha$ is the ridge orientation.

that only mechanically grown ice was included (Wadhams, 2000).

\subsubsection{Keel area coefficient $K_{A}$}

In the present study the keel cross sectional shape below the threshold was studied by investigating the keel area coefficient $K_{A}$ (eq. 4). To highlight that geometry parameters $w_{k}$ and $A_{k}$ are associated with a virtual constant ice velocity $\left(\bar{v}_{i c e}\right)$ we label these in the following with a hat (i.e. $\hat{A}_{k}$ ).

$$
K_{A}=\frac{\hat{A}_{k}^{*}-\hat{A}_{k, \text { triang }}}{\hat{A}_{k, \text { triang }}}
$$

where $\hat{A}_{k}^{*}$ is the keel area at depths greater than the threshold and is defined in eq. 5 while $\hat{A}_{k, \text { triang }}$ is given in eq. 6.

$$
\begin{aligned}
\hat{A}_{k}^{*}= & \frac{1}{2} \sum_{j=1}^{N}\left(t_{j+1}-t_{j}\right) \cdot \bar{v}_{i c e} \\
& \cdot\left(h_{i}\left(t_{j+1}\right)+h_{i}\left(t_{j}\right)-2 \cdot h_{\text {thres }}\right)
\end{aligned}
$$

where $\bar{v}_{i c e}$ is the virtual mean drift speed for the ridge and $t$ refer to time. $N$ is defined as in eq. 2 .

$$
\hat{A}_{k, \text { triang }}=\frac{1}{2}\left(h_{k}-h_{\text {thres }}\right) \cdot \hat{w}_{k}
$$

where

$$
\hat{w}_{k}=\left(t\left(P_{4}\right)-t\left(P_{1}\right)\right) \cdot \bar{v}_{i c e}
$$
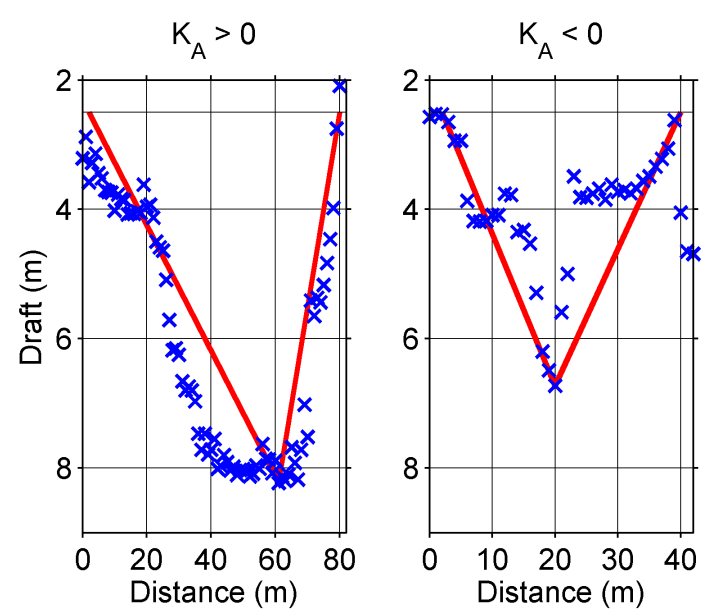

Figure 4: An example of the difference in keel area coefficient $\left(K_{A}\right)$. The blue crosses are measurements while the red line is a hypothetical triangular ridge spanning the area between the deepest point and the width of the ridge. The black line at $2.5 \mathrm{~m}$ is the threshold value.

The virtual mean drift speed $\left(\bar{v}_{i c e}\right)$ is both in the numerator and denominator of eq. 4 and thus canceled out. This shows that $K_{A}$ is independent of the drift speed but rely on the assumption that ridges drift with constant drift speed when observed by the ULS. This is justified by the fact that most ridges $(>99 \%)$ were observed for less than 10 minutes. $K_{A}$ is also independent of the ridge orientation as long as the cross section of the keel is identical into the $\mathrm{x}-\mathrm{z}$ plane and the spacing in the $\mathrm{x}$ direction is uniform.

$K_{A}$ reveal whether the keel area at depths greater than the threshold $\left(\hat{A}_{k}^{*}\right)$ is underestimated or overestimated by a hypothetical triangular cross section spanned by the keel width and the keel draft (solid red line in Fig. 4 and eq. 6). Because the keel draft $h_{k}$ is the deepest point within the ridge, $K_{A}$ must vary between $-1\left(\hat{A}_{k}=0\right)$ and 1 (rectangular keel with draft $h_{k}>h_{\text {thres }}$ ). Figure 4 shows two real ice ridges and how the cross sectional area is underestimated $\left(K_{A}=0.26\right)$ and overestimated $\left(K_{A}=-0.29\right)$ by a triangular cross section (spanned by the solid red line).

Equation 8 give the area of a trapezoidal keel with a shape enclosed by the $h_{\text {thres }}$ and the stapled line between $P_{1}, P_{2}, P_{3}$ and $P_{4}$ in Fig.2.

$$
\hat{A}_{k, \text { trapz }}=\frac{1}{2}\left(h_{k}-h_{\text {thres }}\right) \cdot\left(\hat{w}_{k}+\hat{w}_{k, b}\right)
$$

where $\hat{w}_{k, b}$ is the keel bottom width and defined as:

$$
\hat{w}_{k, b}=\left(t\left(P_{3}\right)-t\left(P_{2}\right)\right) \cdot \bar{v}_{i c e}
$$


where $P_{2}$ and $P_{3}$ are points at $h_{k}$ and defines the bottom of an idealized trapezoidal keel.

When eq. 8 is inserted into eq. 4 replacing $\hat{A}_{k}^{*}$ we get that $K_{A}$ for a trapezoidal keel is expressed by the keel bottom width to keel width ratio (eq.10).

$$
K_{A}=\frac{\hat{w}_{k, b}}{\hat{w}_{k}}
$$

\subsubsection{Symmetry}

Symmetry of a ridge keel could be quantified as the location of the deepest point of the keel, $\lambda_{1}$ (eq. 11) and as the centroid of the keel, $\lambda_{2}$ (eq. 12). $\lambda_{1}$ and $\lambda_{2}$ determines the ratio of the distance from the keel edge to the deepest point/centroid to the keel width. Both $\lambda_{1}$ and $\lambda_{2}$ are dimensionless.

$$
\begin{gathered}
\lambda_{1}=\frac{\left(t\left(h_{k}\right)-t\left(P_{1}\right)\right) \cdot \bar{v}_{i c e}}{\hat{w}_{k}} \\
\lambda_{2}=\frac{1}{2} \frac{\sum_{j=1}^{N}\left(t_{j+1}+t_{j}\right) \cdot \bar{v}_{i c e} \cdot \hat{A}_{j}}{\hat{A}_{k} \cdot \hat{w}_{k}}
\end{gathered}
$$

where $\mathrm{N}+1$ is as for eq. 2 and $\hat{A}_{j}$ is:

$$
\hat{A}_{j}=\frac{1}{2}\left(t_{j+1}-t_{j}\right) \cdot \bar{v}_{i c e} \cdot\left(h_{i}\left(x_{j+1}\right)+h_{i}\left(x_{j}\right)\right)
$$

Like for $K_{A}$ we could cancel out $\bar{v}_{i c e}$ and thus are both $\lambda_{1}$ and $\lambda_{2}$ independent of the drift speed. The symmetry is also independent of ridge orientation based on the assumption that the keel cross sectional shape is identical in the X-z plane. A perfectly symmetrical keel would have both $\lambda_{1}$ and $\lambda_{2}$ equal to 0.5 .

\subsection{Drift speed}

The ice drift speed was not measured at site and the ice drift speed was estimated to obtain a spatial reference in the $\mathrm{x}$-direction (Fig. 2). Ice drift is a function of the wind, current, Coriolis force, internal ice stress and sea surface tilt (Leppäranta, 2011). We apply a simple free ice drift model (eq. 14, after Leppäranta, 2011, pg. 188) . The model includes wind $\left(V_{\text {wind }}\right)$, current $\left(V_{\text {current }}\right)$, and the Coriolis force which offsets the wind $\theta$ degrees to the right in the northern hemisphere. It does not include the internal friction of ice and the sea surface tilt. The model is applicable for calculation of drift of single ice floes or when the ice concentration is less than about $80 \%$ (Leppäranta, 2011).

$$
V_{\text {ice }}=\left|\beta \cdot \cos (\theta) \cdot \mathbf{V}_{\text {wind }}+\mathbf{V}_{\text {current }}\right|
$$

where $\beta$ is the wind factor and $\theta$ is the deviation angle between the wind-driven ice drift and the wind.
A representative surface wind factor $(\beta)$ is $2.5 \%$ (Leppäranta, 2011) while $\theta$ typically is $30^{\circ}$ in the Arctic. The wind was not measured at site and we used wind data from the ERA-Interim hindcast archive (Dee et al., 2011). The hindcast archive provides wind speed $10 \mathrm{~m}$ above sea level every 6 hours. The current was measured at site with an Aanderaa RDCP 600 which sampled the current velocity once per hour at $40 \mathrm{~m}$ water depth. The recorded current velocity was the mean velocity of 300 measurements (pings) over 282 seconds. Both the wind and the current velocity was linearly interpolated to match the draft measurements which were sampled every 2 seconds.

The calculated ice drift speed (eq. 14) is dominated by the contribution from the wind. By removing the current term, the mean ice drift $\left(\bar{V}_{i c e}\right)$ decreased from 0.21 to $0.18 \mathrm{~m} / \mathrm{s}$ and the maximum from 0.68 to $0.51 \mathrm{~m} / \mathrm{s}$. Although the Coriolis was included it had a marginal effect on the mean ice drift speed $(-0.4 \%)$. The keel width and keel area was close to proportional with the wind factor $(\beta)$.

The estimated drift speed was compared with drift buoys that passed close to the area in 2008-2009 (Rigor, 2002). The position of these buoys was logged every 12 hours and a minimum drift speed was estimated based on assumed straight trajectories between each position. Only one drift buoy passed in the vicinity $\left(4.5-8.5^{\circ} \mathrm{W}\right.$, $78-80^{\circ} \mathrm{N}$ ) in our measurement period while 11 more buoys passed when the whole of 2008 and 2009 was included. The mean drift speed of the 12 buoys was 0.27 $\mathrm{m} / \mathrm{s}$ which is $30 \%$ higher than our estimated mean. The highest estimated velocity $(0.68 \mathrm{~m} / \mathrm{s})$ was lower than that observed by Yulmetov et al. (2013) who measured velocities up to $1.1 \mathrm{~m} / \mathrm{s}$ in 2012/2013 a value which is close to the highest drift speed $(1 \mathrm{~m} / \mathrm{s})$ estimated for a buoy over 12 hours.

\subsection{Smoothing}

A running average filter was used to avoid that the Rayleigh criterion divided a single ridge into several ridges due to a local minimum within a ridge. A window size of 10 seconds was found sufficiently short to avoid any unwanted effects on ridge parameters (Fig. 5). The impact of the smoothing depends on the spatial resolution of the ice ridge. An ice ridges with low spatial resolution (high drift speed) would be more rounded and its maximum draft would be more reduced than an ice ridge with high spatial resolution (Ross et al., 2014). The time series was smoothed with this method before it was converted to a spatial series. No interpolation to evenly spaced values was used which mean that the identification of the ridges will be identical whether they 
are identified from the temporal or the spatial data. The window size of 10 seconds corresponds to a horizontal distance which on average is $2.1 \mathrm{~m}$ (eq. 14) which is close to the footprint of the IPS $(1.6 \mathrm{~m})$. Compared to ridges identified from non-smoothed data it reduced the number of identified ridges deeper than $5 \mathrm{~m}$ from 40550 to 30186 .

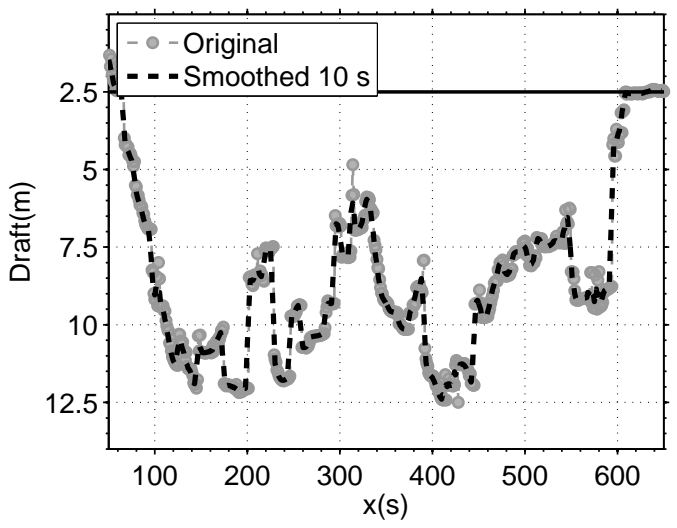

Figure 5: An example of the effect of smoothing with a 10 second smoothing window.

\section{Results}

\subsection{Draft, shape, symmetry, directly derived from time- series}

\subsubsection{Draft}

Ridge keel draft varied from 5 to $25 \mathrm{~m}$ and was on average $\bar{h}_{k}=7.3 \mathrm{~m}$ (hereafter the bar above a variable refers to the parameter mean). An exponential distribution, with $\mu=2.3$ (mean subtracted minimum draft), describes the distribution of observed drafts well (Table 2). The mean value increased from 7.1 to 7.3 after smoothing the data.

\subsubsection{Keel shape}

The mean keel area coeffient $\left(\bar{K}_{A}\right)$ was 0.17 and the standard deviation was 0.21 . $79 \%$ of the ridges had a keel area coefficient higher than 0 which suggest that the keel cross sectional area of these ridges would be underestimated by a triangular cross section $\left(A_{k, t r i a n g}\right)$. As $K_{A}$ has obvious upper and lower limits, its probability distribution should include this. By adding 1 and dividing by 2 we obtain a modified keel area coefficient (eq. 15) that can be fitted to a beta distribution with limits 0 and 1.

$$
K_{A}^{*}=\frac{K_{A}+1}{2}=\frac{A_{k}^{*}}{2 \cdot A_{k, \text { triang }}}
$$

The best fit parameters $a$ and $b$ (from maximum likelihood) was 12.2 and 8.8 respectively (Table 2).

Davis and Wadhams (1995) suggest that old ridges approximate a semi-elliptical keel shape as they get more weathered with time. The keel area of a semielliptical keel $\left(A_{k, \text { semi }}\right)$ could be calculated from the keel width $\left(w_{k}\right)$ and keel draft (eq. 16). When eq. 16 is inserted for $A_{k}^{*}$ in eq. 4 we get that a semi-elliptical keel correspond to a $K_{A}$ of 0.57 .

$$
A_{k, \text { semi }}=\frac{\pi \cdot\left(h_{k}-h_{\text {thres }} \cdot w_{k}\right)}{2}
$$

Now we have two keel shapes (triangular and semielliptical) where each shape corresponds to $K_{A}$ of 0 and 0.57 respectively. Thus we could indicate the keel shape of the observed ridges by using the keel area coefficient as a discriminator (Table 1, Fig. 6). From Fig. 6 we see that $21 \%$ of the ridges have a keel cross sectional area less than triangular $\left(K_{A}^{*}<0.5\right)$. Similarly have $2 \%$ of the ridges a cross sectional area greater than semi-elliptical $\left(K_{A}^{*}>0.785\right)$. From Table 1 we observe that the mean keel draft and mean keel width and mean keel area all decrease with increasing $K_{A}$. The deepest ridges, represented by a minimum draft of $15 \mathrm{~m} \mathrm{(382}$ ridges), had $\bar{K}_{A}=0.12$.

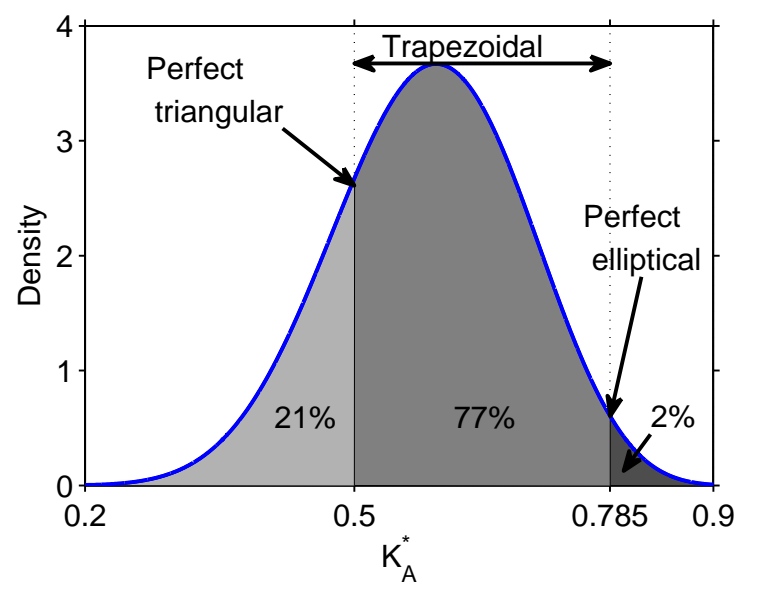

Figure 6: Probability density of $K_{A}^{*}$.

\subsubsection{Keel symmetry}

Ridge keels are on average symmetric and the mean keel crest location $\left(\bar{\lambda}_{1}\right)$ and the mean keel centroid $\left(\bar{\lambda}_{2}\right)$ were both 0.5 . The standard deviation of $\lambda_{1}(0.2)$ was considerably higher than $\lambda_{2}(0.05)$ suggesting that the location of keel crest vary more than the centroid of the keel. A beta distribution could be used to describe the distribution of both symmetry parameters (Table 2). 
Table 1: Mean draft, width and area per interval in Fig.6. $N$ refer to the number of ridges.

\begin{tabular}{lccc}
\hline$K_{A}$ & $<0$ & $0-0.57$ & $>0.57$ \\
\hline$K_{A}^{*}$ & $<0.5$ & $0.5-0.785$ & $>0.785$ \\
$N$ & 6375 & 23114 & 697 \\
$\bar{h}_{k}(m)$ & 7.5 & 7.2 & 6.9 \\
$\bar{w}_{k}(m)$ & 32 & 28 & 23 \\
$\bar{A}_{k}\left(m^{2}\right)$ & 163 & 164 & 146 \\
\hline
\end{tabular}

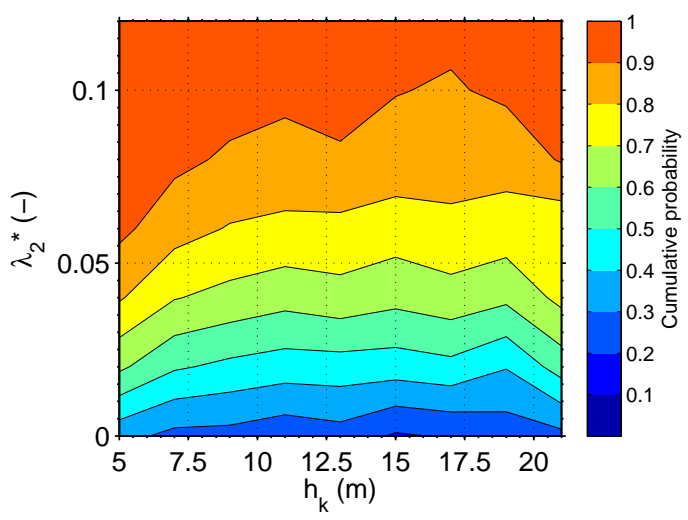

Figure 7: $h_{k}$ vs $\lambda_{2}^{*}$. The $\lambda_{2}$ values are folded such that $\lambda_{2}^{*}$ give the deviation in absolute value from $\lambda_{2}=0.5$.

Fig. 7 display $\bar{h}_{k}$ vs $\lambda_{2}^{*}$ and illustrate that greater asymmetry is associated with deeper ridges. However $\bar{\lambda}_{2}=0.5$ regardless of draft.

\subsection{Keel width and keel area derived from spatial data}

The study of the keel width and keel area required the conversion to a spatial series applying the estimated drift speed.

The mean observed keel width ( $\left.w_{k, o b s}\right)$ was $28 \mathrm{~m}$ with standard deviation of $30 \mathrm{~m}$. A log-normal distribution could be used to described observed keel widths (Table 2).

On average the observed keel cross sectional area $\left(A_{k, o b s}\right)$ was $164 \mathrm{~m}^{2}$ with a standard deviation of 230 $m^{2}$. The probability distribution of the keel area was well described by a log-normal distribution (Table 2).

\subsection{Sensitivity}

We studied the sensitivity of the estimated parameters to changes in window size and threshold value. The sensitivity was measured as the difference in percentage compared to the parameter mean. The tested window sizes were 6 seconds and 22 seconds while the tested thresholds were $2 \mathrm{~m}$ and $3 \mathrm{~m}$. Fig. 8 show the sensitivity of each parameter. All outcomes that deviated less than $1 \%$ were considered minor and not included in Fig. 8. This includes all outcomes on $\bar{h}_{k}, \bar{\lambda}_{1}$ and $\bar{\lambda}_{2}$.

Keel width, keel area and the keel area coefficient varied with more than $\pm 10 \%$ both for variable window size and threshold. The number of ridges $(N)$ was more sensitive to changes in the window size than threshold and decreased with $23 \%$ when the window size increased from $2.5 \mathrm{~m}$ to $3 \mathrm{~m}$. The sensitivity in $N$ also followed that of $\bar{K}_{A}$ and was remarkably equal for changes in the window size.

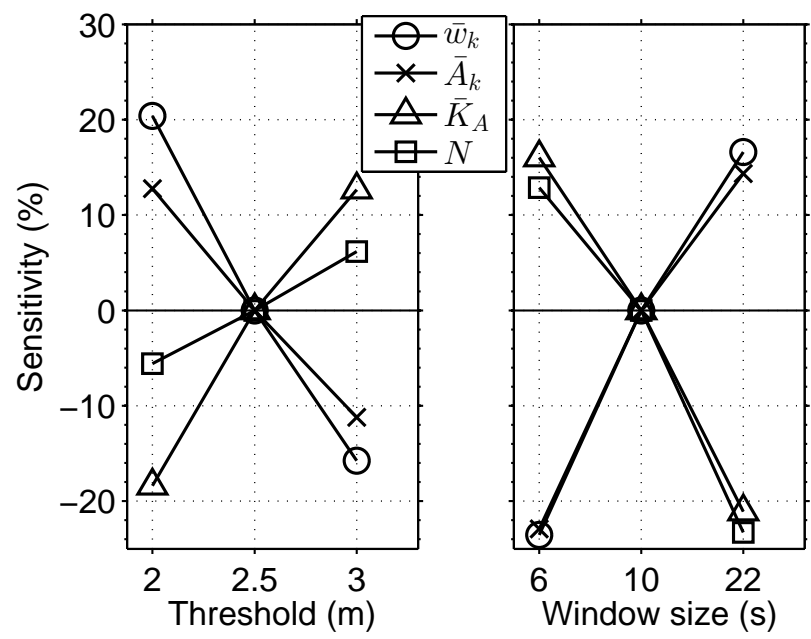

Figure 8: The sensitivity of each parameter to changes in window size and threshold. $N$ refer to total number of ridges and was initially 30186.

\section{Discussion}

\subsection{Keel shape, draft and symmetry}

The keel cross sectional area of all ridge keels was investigated using the keel area coefficient. The keel cross sectional area of $79 \%$ of the ridges would be underestimated by a triangular keel shape. Another approach to investigate keel shape is that by Melling and Riedel (1995). Instead of analyzing each individual ridge, they derive an expression for the probability density of draft within each keel on the assumption that keel shapes are independent of their maximum draft and that their width is proportional to the maximum draft. Then the draft within each keel is exponentially distributed and a function of the probability density of draft and the frequency of maximum keel draft only. Based on empirical exponents of the latter two probability distributions Melling and Riedel (1995) presents an exponent (or efolding scale) of 26.5 corresponding to a cusp-shaped 
Table 2: Summary statistics of keel geometry derived from 30186 ridges. The correlation between expected and observed frequencies was $>0.99$ for all the distributions.

\begin{tabular}{cccccccccc}
\hline & Unit & Mean & Max & $\sigma$ & Distribution & Parameters $^{b}$ & $\chi^{2}$ & $\mathrm{p}^{d}$ & dof $^{c}$ \\
\hline$h_{k}$ & $\mathrm{~m}$ & 7.29 & 25 & 2.27 & Exponential & $\mu=7.29$ & 18.3 & 0.15 & 13 \\
$w_{k}$ & $\mathrm{~m}$ & 28.4 & 870 & 30.2 & Log-normal & $\mu=2.98, \sigma=0.87$ & 61.2 & 0.00 & 12 \\
$A_{k}$ & $m^{2}$ & 164 & 5919 & 230 & Log-normal & $\mu=4.61, \sigma=0.97$ & 2.58 & 0.98 & 12 \\
$\lambda_{1}$ & - & 0.49 & - & 0.20 & Beta & $\mathrm{a}=2.63, \mathrm{~b}=2.72$ & 5.01 & 0.96 & 12 \\
$\lambda_{2}$ & - & 0.50 & - & 0.05 & Beta & $\mathrm{a}=45.8, \mathrm{~b}=46.6$ & 28.0 & 0.01 & 12 \\
$K_{A}{ }^{a}$ & - & 0.58 & - & 0.11 & Beta & $\mathrm{a}=12.2, \mathrm{~b}=8.75$ & 22.7 & 0.03 & 12 \\
\hline
\end{tabular}

a. The distribution is fitted to $K_{A}^{*}$ (eq. 15).

b. The distribution parameters are found by maximum likelihood.

c. Minimum number of expected observations was greater than 5 per bin.

d. The p-value reveals the goodness of fit described by the $\chi^{2}$-test. A p-value less than 0.05 suggest that the distribution does not provide a good fit for the observations on a $5 \%$ significance level.

keel (steepen with increasing draft). This suggests that a ridge keel on average would be overestimated by a triangular keel shape. We repeated this exercise with the current dataset and found an exponent of 17.8. This may also be interpreted to represent a cusp-shaped keel on average. Whether to quantify keel shape with the method in the current study or the method presented by Melling and Riedel (1995) depends on the application and each method has its advantages and disadvantages. The current findings also support Hopkins (1996, 1998) who found, when modeling the ridge formation, that the mean ridge keel shape was trapezoidal because the ridges became wider instead of deeper when a given depth was reached. Real ridge keel shapes vary substantially, but simplified characterization may be necessary for engineering use and ISO19906 (2010) and the two review papers of Timco and Burden (1997); Strub-Klein and Sudom (2012) support a triangular and trapezoidal shape.

We found that $79 \%$ of the ridges in this study would be underestimated by a triangular cross section $\left(K_{A}>\right.$ $0)$. Could this indicate something about the age composition of ridges? While first-year ridges are typically considered to be triangular (Timco and Burden, 1997), old ridges are typically considered to be trapezoidal (Timco and Burden, 1997) or even semi-elliptical in shape (Davis and Wadhams, 1995). We know that the ridges in the Fram Strait are a mixture of first-year ice and old ice and that they originate from the Laptev Sea and East Siberian Sea (Hansen et al., 2013). Let us assume that all ridges in September-October 2008 were old ridges (2196 ridges). These ridges had a mean keel area coefficient of 0.22 . For the remaining part of the deployment-season (November-August) there was a mixture of FY ridges and old ridges and the mean keel area coefficient was 0.16 . Then if we assume that all the FY ridges are triangular (with $K_{A}=0$ ) we find that the fraction of old ridges must be $0.16 / 0.22=73 \%$. This is a considerably higher fraction of old ridges than what might be expected and suggest that also first year ridges have a cross sectional area greater than triangular.

The nominal field-of-view of the sonar is decided by the sonar beamwidth and the sonar depth and is greater than the effective field-of-view which his determined by a variety of factors such as transmitted power, target strength, receiver gain etc (Melling et al., 1995). In Ekeberg et al. (2014, in prep.) the nominal beamwidth was used to study the effect of footprint widening on $K_{A}$, which is similar to the analysis by Rodrigues (2011). One finding was that a ULS, at $50 \mathrm{~m}$ water depth with the same beamwidth as in this study, would increase $K_{A}$. An effect which decreased rapidly with keel draft/size. For a $5 \mathrm{~m}$ deep keel, $K_{A}$ would increase with up to 0.05 . This is not sufficiently high to explain the present deviation from triangular keel shape but suggest that the presented mean $K_{A}$ in reality is lower and could be reduced by 0.05 for the smallest ridges.

For standards and design calculations the use of a simple geometrical model has been commonplace. However the discretized numerical models now available enable the effect of any keel geometry to be modeled. The large sample of ridge sections compiled through this project provide opportunities for more realistic calculations using such models. Ridge loads on ships and structures are not only determined by the keel draft but also depends on the cross sectional area of the ridge keel (Riska et al., 1997; Dalane et al., 2009). Thus, an underestimated keel area could lead to underestimated loads. The 
present finding about the keel area coefficient demonstrate that, when keel geometry is derived from ULS data, a triangular keel shape would underestimate the keel cross sectional area. Both on average and for the deepest keels. Consequently would a trapezoidal cross section be a more suitable generalized keel shape in a deterministic and a probabilistic framework.

However, if you instead would assume a triangular keel formed by the draft and keel width as determined by discrete measurements (like Timco and Burden, 1997) it is not obvious if the keel cross section would be underestimated or overestimated. Thus, how the current result translate to other measurements remains an open question.

Timco and Burden (1997); Davis and Wadhams (1995); ISO19906 (2010); Strub-Klein and Sudom (2012) all state that ridge shapes vary greatly but still suggest working from the assumption that the keel shapes are symmetrical. This is supported by the present findings which reveal that on average the keel crest and the centroid of the keel are both in the center of the keel. However there was a trend that the most asymmetric ridges were slightly deeper on average (Fig. 7). This could not be explained by splitting of the larger ridges as a study of the ridges with no neighboring ridge (in total $50 \%$ of all the ridges) gave the same trend. A more plausible cause could be that larger ridges have a more complex geometry as they more often are formed through several ridging events so that they have a natural asymmetry.

Keel draft is the most common, and such an important, geometric input parameter into models for calculation of ice ridge keel loads. The present study showed that it was exponentially distributed which is in line with previous investigations (Wadhams, 1983; Melling and Riedel, 1995; Wadhams, 2000; Ekeberg et al., 2012).

In this area the most recent study of ice ridge drafts was conducted by Wadhams et al. (2011). They studied ice ridges identified from data sampled with a submarine mounted ULS in March 2007. They found that the mean draft between $81.7^{\circ} \mathrm{N}$ and $83.8^{\circ} \mathrm{N}$ was $7.9 \mathrm{~m}$. In our study the mean keel draft was $7.4 \mathrm{~m}$ in March 2009 (at $79^{\circ} \mathrm{N}$ ). That the mean keel draft decreased from 2007 to 2009 and/or with latitude was expected. In this period (2007-2009) both the overall ice thickness and the age of the ice that was transported down the Transpolar Drift Stream decreased (Hansen et al., 2013). The decrease in ice thickness and age is associated with a reduction in the mean keel draft (Ekeberg et al., 2014, submitted). That mean keel draft decrease with latitude could also be due to melting of the keel crest as it drift southwards as discussed in Davis and Wadhams (1995).

\subsection{Ridge keel width and area based on drift speed es- timate}

Observed keel widths were found to best fit a lognormal distribution which is equal to findings by Davis and Wadhams (1995) and Marcellus et al. (2011) who studied ridges from submarine data in the Transpolar Drift and the Arctic Ocean respectively. Davis and Wadhams (1995) found that the mean keel width close to our area was $54 \mathrm{~m}$ with a corresponding mean draft of 7.6 $m$ (in 1987). This is $+100 \%$ greater than our observed mean keel width which was $26.8 \mathrm{~m}$ in March 2009. Although their mean keel draft is greater than our observed mean keel draft $(7.4 \mathrm{~m})$ this cannot explain the deviation. However, Davis and Wadhams (1995) only include ridges which are identified in both ULS data and the SS data (44 in total). This approach probably excludes the small/narrow ridges and is indicated in their table 3 where the narrowest keel was $20 \mathrm{~m}$ wide. In our study no ridge keels deeper than $5 \mathrm{~m}$ were excluded and $50 \%$ of the ridges were less than $20 \mathrm{~m}$ wide. If we only considered ridges more than $20 \mathrm{~m}$ wide the mean keel width becomes $46 \mathrm{~m}$. The keel width was perhaps also measured from the actual level ice surface by Davis and Wadhams (1995) and not a fixed threshold like our study. This would lead to a greater keel width and is discussed in the next section. However, Davis and Wadhams (1995) corrected for the ridge orientation which means that they report $\bar{w}_{k, t r u e}$ which should be lower than $\bar{w}_{k, o b s}$ reported in this study. To sum up the comparison above, the results in the present study and Davis and Wadhams (1995) are not directly comparable. Considering the small sample used by Davis and Wadhams (1995) and that they only included a subsample of the ridges the results could be considered as similar.

The keel cross sectional area has gained little attention in previous ridge keel investigations despite its importance in keel loads. We found that the keel area was best described by a log-normal distribution which is the same as Marcellus et al. (2011) who investigated ULS data sampled by a submarine in the Beaufort Sea.

Both the measured keel width and keel area are associated with many error sources which relate to measurement technique (ULS vs drilling, orientation), instruments settings (beamwidth) and post processing (smoothing, drift estimate and ridge identification criterion). In the following the impact of different error sources on keel width and keel area are discussed.

\subsubsection{Discrete vs continuous measurements}

The keel width and keel area derived from ULS measurements in this study would not be the same if we 
were to discretely measure the same ridges. This discrepancy is caused by two important differences when measuring discretely. First, ridge orientation is known and the keel width and the keel area would be measured close to perpendicular to the keel crest which give $w_{k, t r u e}$ and $A_{k, t r u e}$ (see Fig. 3). Second, the level ice surface is identified on each side of the ridge rather than given a fixed value as in the present study. While the ridge orientation (in a linear segment) is unknown and cannot be measured by the ULS the level ice surface could be identified through some routine which quantify the ice thickness next to the ice ridge. However, it is not necessarily an advantage to identify the level ice thickness (draft in our case) with respect to derivation of keel geometry. Then there would be a strong dependency between the level ice thickness next to the keel and the derived keel width which makes further use challenging. As an example, take a triangular keel with a $5 \mathrm{~m}$ deep keel and a keel angle of $30^{\circ}$. Let the level ice be either $1 \mathrm{~m}$ or $2 \mathrm{~m}$. This gives a keel width of either 13.8 or $10.4 \mathrm{~m}$ or a difference of $25 \%$ just based on the level ice. In fact this illustrate very well how difficult it could be to compare keel geometry statistics derived from discretely measured ice ridges (like those in Timco and Burden, 1997; Strub-Klein and Sudom, 2012) with statistics derived from ULS data like shown in the present study.

\subsubsection{Footprint widening}

It can be shown that either side of a ridge keel with sloping sides and which is not flanked by another ridge will increase with half a footprint diameter (Ekeberg et al., 2014, in prep.). In this study half a footprint (at waterlevel) is $0.75 \mathrm{~m}$ which means that all ridges flanked by level ice will be widened by approximately $1.5 \mathrm{~m}$. A similar increase occurs for the keel area. An idea of the size of this error could be obtained from a simple example with a triangular keel cross section with $h_{k}=5 \mathrm{~m}, w_{k}=20 \mathrm{~m}, h_{\text {thres }}=2.5 \mathrm{~m}$ with equal beamwidth and depth as in this study. Then the observed area would be $8 \%$ greater than the theoretical (not shown but based on Ekeberg et al., 2014, in prep.).

\subsubsection{Smoothing (and windowsize)}

A property of the used ridge identification criterion is that a single low/high outlier is sufficient for the criterion to define a start/end of a ridge. Thus, to reduce the size and effect from outliers the data was smoothed prior to ridge identification. The smoothing method, a running average filter, have window size as only input. The effect from an increase in window size was less ridges and an increase in the mean keel width and mean keel area (Fig. 8). These are expected effects because an increase in window size will merge more ridges as it reduces the local depressions/crests of ice draft. When two or more ridges are merged the width of the final ridge must be wider than the mean of the ones that were merged and thus lead to an increase in the mean keel width (and area). The sensitivity to changes in window size also demonstrates how important it is to apply the same smoothing method if keel geometry statistics are to be compared.

A second smoothing effect could be introduced if the spatial data is transformed to equidistantly spaced records (Melling et al., 1995). The submarine mounted ULS data at NSIDC (NSIDC, 2006) are converted to equidistant records which for example Marcellus et al. (2011) base their results on.

\subsubsection{Drift speed}

Ideally the sea ice drift is measured but in the present study this was estimated based on an assumption about free drift. Leppäranta (2011) suggest that this is valid for ice concentration below $80 \%$. At our location this might be valid in part of the season but we expect that the ice concentration often is greater than $80 \%$ between November and April (Ekeberg et al., 2014, submitted). However, at higher ice concentration the ice stress should be included which primarily result in a reduction in inertial energy and decrease the estimated ice drift speed. Instead of applying the measured current, Leppäranta (2011) suggest using the geostrophic current. This current, unaffected by surface friction, should be greater than the measured current and could lead to an underestimated drift speed. However, because the wind speed primarily governs the estimated keel width and keel area, the error in current must be high to produce a significant error in the drift speed. Thus we suggest that, if our drift estimate contains error, it originates from either the wind factor $(\beta)$ or the wind. The wind factor $(\beta)$ of $2.5 \%$ is in line with the study by (Spreen et al., 2011) who compared daily ice drift calculated from SSM/I satellite records and wind speed $10 \mathrm{~m}$ above sea level taken from different re-analysis products (including ERA-Interim). They found these to correlate well $(r=0.8)$ and that the drift speed was about $2.5 \%$ of the wind speed in the Fram Strait. To test the wind speed estimate the wind in the drift model was replaced by a similar product, the NCEP Re-Analysis 2 wind speed (Kanamitsu et al., 2002). Overall this gave the same results (see Table 2) with a mean keel width of $28.7 \mathrm{~m}$, a standard deviation of $28.2 \mathrm{~m}$ and similarly a mean keel area of $165 \mathrm{~m}^{2}$ with a standard deviation of $215 \mathrm{~m}^{2}$. Although we do not suspect that the drift speed estimate is 
wrong any errors in the mean may be compensated for by adjusting the wind factor because all derived parameters are close to proportional to this factor.

\subsubsection{Ridge identification criterion and threshold}

Both keel width and keel area strongly depends on the threshold value $\left(h_{\text {thres }}\right)$ which is input in the ridge identification criterion. For a ridge not flanked by any other ridges, an increase in threshold must reduce its keel width and keel area. This contributes to the $12-15 \%$ decrease in mean keel width and mean keel area when the threshold is increased from $2.5 \mathrm{~m}$ to $3 \mathrm{~m}$ (Fig.8). However, a second and greater cause for the decrease in the mean width is more splitting of ridges by the ridge identification criterion. This is reflected in an increase in the number of ridges (Fig.8). When the threshold decreases it leads to an increase in distance between a local depression of low draft within ridges and the threshold. While this local depression was sufficiently low to split the ridge at a higher threshold this will not be the case when the threshold decrease. Thus some ridges which initially were split by the Rayleigh criterion now contribute to an increase in the mean keel width as they are not split.

The keel width is also a function of the criterion which is used for identifying ridges. Instead of using the Rayleigh criterion we could have used a criterion that defines a ridge as every feature where consecutive ice draft observations are above the threshold (the Cutoff criterion, Ekeberg et al., 2012). This criterion would lead to an increase in the mean keel width and fewer ridges applying the same threshold and minimum draft. This is caused by two effects. One is that the Rayleigh criterion divides ridges which the Cutoff criterion interprets as one which favors a higher mean keel width for the Cutoff criterion. The second reason is that the Cutoff includes more of the ice on the flanks of the ice ridge. On the same data as we used in this study the sum of all keel widths increase with $15 \%$ when the Cutoff criterion is compared with the Rayleigh criterion.

This just demonstrates the differences and challenges that arise from the chosen identification criterion and also the input parameters. It illustrates very well why the current ice ridge criterion, threshold value and minimum draft were chosen since this allows comparison with previous studies.

\section{Conclusions}

A total of 30186 ridges deeper than $5 \mathrm{~m}$ were identified and analyzed with respect to their geometry. The mean keel draft was $7.3 \mathrm{~m}$ while the deepest was $25 \mathrm{~m}$ deep. The conversion from a temporal data to a spatial data was accomplished by estimating the ice drift assuming free drift. From the spatial data we found that the mean keel width was $28 \mathrm{~m}$ while the mean keel cross section was $164 \mathrm{~m}^{2}$.

Studies of ridge shape based on temporal data suggest that ridges on average are symmetric both with respect to the centroid of the keel and the location of their deepest point.

Through examination of the keel shape coefficient of individual ridges we observed that the keel cross sectional area would be underestimated by a triangular cross section for $79 \%$ of the ridges. This approach suggests a triangular keel shape would underestimate the keel cross sectional area so that the ridge loads could be underestimated. Since a trapezoidal keel shape would give a conservative ridge load estimate we suggest the use of such a shape in ridge action estimations. We found that the mean trapezoidal keel, including both first year ridges and old ridges, had a keel bottom-width which was $17 \%$ of the keel width. For the deepest keels ( $>15$ $\mathrm{m})$ the keel bottom width was on average $12 \%$ of the keel width.

\section{Acknowledgment}

Met.no and Ivar A. Seierstad is acknowledged for preparing and sharing of ERA-INTERIM data. The sharing of NCEP/DOE 2 Reanalysis data by the NOAA/OAR/ESRL PSD is acknowledged. The authors also wish to acknowledge the support from the Research Council of Norway through PetroRisk and the Centre for Research-Based Innovation SAMCoT.

\section{References}

Bowen, R.G., Topham, D.R., 1996. A study of the morphology of a discontinuous section of a first year arctic pressure ridge. Cold Regions Science and Technology 24, 83-100. doi:10.1016/0165232X(95)00002-S.

Croasdale, K., 1980. Ice Forces on Fixed Rigid Structures, 1st IAHR State-of-the-Art Report on Ice Forces on Structures. Technical Report Special Report 80-26. CRREL,Hanover, N.H., USA. Pp. 34106.

Croasdale, K., Cammaert, A., Metge, M., 1994. A method for the calculation of sheet ice loads on sloping structures, in: Proceedings of the IAHR'94 Symposium on Ice, Trondheim, Norway., pp. 874875.

Dalane, O., Aksnes, V., Løset, S., Aarsnes, J.V., 2009. A moored arctic floater in first-year sea ice ridges. ASME Conference Proceedings 2009, 159-167. doi:10.1115/OMAE2009-79945.

Davis, N.R., Wadhams, P., 1995. A statistical analysis of arctic pressure ridge morphology. J. Geophys. Res. 100, 10915-10925. doi:10.1029/95JC00007. 
Dee, D.P., Uppala, S.M., Simmons, A.J., Berrisford, P., Poli, P., Kobayashi, S., Andrae, U., Balmaseda, M.A., Balsamo, G., Bauer, P., Bechtold, P., Beljaars, A.C.M., van de Berg, L., Bidlot, J., Bormann, N., Delsol, C., Dragani, R., Fuentes, M., Geer, A.J., Haimberger, L., Healy, S.B., Hersbach, H., Hólm, E.V., Isaksen, L., Kållberg, P., Köhler, M., Matricardi, M., McNally, A.P., MongeSanz, B.M., Morcrette, J.J., Park, B.K., Peubey, C., de Rosnay, P., Tavolato, C., Thépaut, J.N., Vitart, F., 2011. The era-interim reanalysis: configuration and performance of the data assimilation system. Quarterly Journal of the Royal Meteorological Society 137, 553-597. doi:10.1002/qj.828.

Doble, M.J., Forrest, A.L., Wadhams, P., Laval, B.E., 2009. Throughice auv deployment: Operational and technical experience from two seasons of arctic fieldwork. Cold Regions Science and Technology 56, 90-97. doi:10.1016/j.coldregions.2008.11.006.

Dolgopolov, Y., Afanasiev, V., Koren'kov, V., Panfilov, D., 1975. Effect of humocked ice on the piers of marine hydraulic structures, in: IAHR The Third International symposium on ice problems, Hanover, New Hampshire. pp. 469-477.

Ekeberg, O., Høyland, K., Hansen, E., 2012. Ice ridge identification methods and analysis of upward looking sonar data from fram strait 2006-2010, in: Li, Z., Lu, P. (Eds.), 21st IAHR International Symposium on Ice, Dalian University of Technology press, Dalian, China. pp. 603-615

Ekeberg, O., Høyland, K., Hansen, E., Tschudi, M., 2014, submitted. Reduction in the number and thickness of ridges in the transpolar drift in the fram strait during 2006-2011, in: 22nd IAHR International Symposium on Ice, Singapore.

Ekeberg, O.C., Høyland, K., Heinonen, J., Hansen, E., 2014, in prep. On ridge keel shapes from upward lookings sonar measurements. to be submitted to Cold Regions Science and Technology .

Hansen, E., Gerland, S., Granskog, M., Pavlova, O., Renner, A., Haapala, J., Løyning, T.B., Tschudi, M., 2013. Thinning of arctic sea ice in fram strait: 1990-2011. J. Geophys. Res. doi:10.1002/jgrc. 20393

Heinonen, J., 2004. Constitutive Modelling of Ice Rubble in First Year Ice Ridge Keel. Ph.D. thesis. Helsinki School of Engineering. Espoo.

Hibler, W. D., I., Weeks, W.F., Mock, S.J., 1972. Statistical aspects of sea-ice ridge distributions. J. Geophys. Res. 77, 5954-5970. doi:10.1029/JC077i030p05954.

Hopkins, M., 1998. Four stages of pressure ridging. J. Geophys. Res. 103(C10), 21883-21891.

Hopkins, M.A., 1996. The effects of individual ridging events on the ice thickness distribution in the arctic ice pack. Cold Regions Science and Technology 24, 75-82. doi:10.1016/0165232x(95)00006-w.

ISO19906, 2010. Petroleum and natural gas industries-arctic offshore structures.

Kanamitsu, M., Ebisuzaki, W., Woollen, J., Yang, S.K., Hnilo, J.J., Fiorino, M., Potter, G.L., 2002. Ncep-doe amip-ii reanalysis (r-2). Bulletin of the American Meteorological Society 83, 1631-1643. doi:10.1175/bams-83-11-1631.

Kärnä, T., Chae, W.R., Shkhinek, K., 2001. Global loads due to firstyear ice ridges, in: Proc.16th Int. Conf. Port and Ocean Eng. under Arctic Cond., Ottawa, Canada, pp. 627-638.

Leppäranta, M., 2011. The Drift Of Sea Ice. Springer-Verlag.

Marcellus, B., McKenna, R., McGonigal, D., Pilkington, R., 2011. Old ice floe and ridge statistics from submarine upward looking sonar data for the beaufort, chukchi and arctic seas, in: POAC'11, Montreal, Canada.

Melling, H., Johnston, P.H., Riedel, D.A., 1995. Measurements of the underside topography of sea ice by moored subsea sonar. Journal of Atmospheric and Oceanic Technology 12, 589-602. doi:10.1175/1520-0426(1995)012;0589:MOTUTO $i 2.0 . C O ; 2$.
Melling, H., Riedel, D., Gedalof, Z., 2005. Trends in the draft and extent of seasonal pack ice, canadian beaufort sea. Geophysical Research Letters 32, L24501. doi:doi:10.1029/2005GL024483.

Melling, H., Riedel, D.A., 1995. The underside topography of sea ice over the continental shelf of the beaufort sea in the winter of 1990 . J. Geophys. Res. 100, 13641-13653. doi:10.1029/95JC00309.

Melling, H., Riedel, D.A., 1996. Development of seasonal pack ice in the beaufort sea during the winter of $1991 ; 1992$ : A view from below. J. Geophys. Res. 101, 11975-11991. doi:10.1029/96JC00284.

Mellor, M., 1980. Ship resistance in thick brash ice. Cold Regions Science and Technology 3, 305-321.

NSIDC, 2006. Submarine upward looking sonar ice draft profile data and statistics. doi:10.7265/N54Q7RWK.

Obert, K.M., Brown, T.G., 2011. Ice ridge keel characteristics and distribution in the northumberland strait. Cold Regions Science and Technology 66, 53-64. doi:10.1016/j.coldregions.2011.01.004.

Pilkington, R., Wright, B., 1991. Beaufort sea ice thickness measurements from an acoustic under ice, upward looking ice keel profiler, in: First International Offshore and Polar Engineering Conference, The International Society of Offshore and Polar Engineers, Edinbourough, United Kingdom. pp. 456-461.

Prodanovic, A., 1979. Model tests of ice rubble strength, in: Proceedings POAC'79, Trondheim, Norway, pp. 89-105.

Prodanovic, A., 1981. Upper bounds of ridge pressure on structures, in: Proceedings POAC '81, Quebec City, P.Q., Canada., pp. 12881302.

Rigor, I., 2002. Iabp drifting buoy pressure, temperature, position, and interpolated ice velocity [2008-2009] (downloaded June 2013). doi: $10.7265 / \mathrm{N} 53$ X84K7.

Riska, K., Wilhelmson, M., Englund, K., Leiviskä, T., 1997. Performance of Merchant Vessels in Ice in the Baltic. Report 52. Winter Navigation Research Board. Helsinki, Finland.

Rodrigues, J., 2011. Beamwidth effects on sea ice draft measurements from u.k. submarines. Cold Regions Science and Technology 65 , 160-171. doi:10.1016/j.coldregions.2010.09.005.

Ross, E., Ekeberg, O.C., Fissel, D., Mudge, T., Kanwar, A., Sadowy, D., 2014. The sensitivity of ice keel statistics to upward looking sonar ice draft processing methods, in: Arctic Technology Conference, Offshore Technology Conference, Houston, USA. p. OTC24601

Rothrock, D., Yu, Y., Maykut, G., 1999. Thinning of the arctic sea-ice cover. Geophys. Res. Lett. 26(23), 3469-3472. doi: $10.1029 / 1999 \mathrm{gl} 010863$.

Serré, N., 2011. Study of the rubble ice action in scale-model ice ridge impact on seabed structures. Ph.D. thesis. Norwegian University of Science and Technology. Trondheim.

Spreen, G., Kwok, R., Menemenlis, D., 2011. Trends in arctic sea ice drift and role of wind forcing: 1992-2009. Geophys. Res. Lett. 38(19), L19501. doi:10.1029/2011GL048970.

Strass, V.H., 1998. Measuring sea ice draft and coverage with moored upward looking sonars. Deep Sea Research Part I: Oceanographic Research Papers 45, 795-818. doi:10.1016/S09670637(97)00065-4.

Strub-Klein, L., Sudom, D., 2012. A comprehensive analysis of the morphology of first-year sea ice ridges. Cold Regions Science and Technology 82, 94-109. doi:10.1016/j.coldregions.2012.05.014.

Timco, G.W., Burden, R.P., 1997. An analysis of the shapes of sea ice ridges. Cold Regions Science and Technology 25, 65-77. doi:10.1016/S0165-232X(96)00017-1.

Vinje, T., Nordlund, N., Kvambekk, A., 1998. Monitoring ice thickness in fram strait. J. Geophys. Res. 103, 10437-10449. doi:10.1029/97JC03360.

Wadhams, P., 1983. The prediction of extreme keel depths from sea ice profiles. Cold Regions Science and Technology 6, 257-266. doi:10.1016/0165-232X(83)90046-0. 
Wadhams, P., 2000. Ice in the ocean. Gordon and Breach, Australia. Wadhams, P., Davis, N.R., 2000. Further evidence of ice thinning in the arctic ocean. Geophys. Res. Lett. 27, 3973-3975. doi:10.1029/2000GL011802.

Wadhams, P., Horne, R., 1980. An analysis of ice profiles obtained by submarine sonar in the beaufort sea. Journal of Glaciology 25 , 401-423.

Wadhams, P., Hughes, N., Rodrigues, J., 2011. Arctic sea ice thickness characteristics in winter 2004 and 2007 from submarine sonar transects. J. Geophys. Res. 116, C00E02. doi:10.1029/2011JC006982

Wadhams, P., Toberg, N., 2012. Changing characteristics of arctic pressure ridges. Polar Science 6, 71-77. doi:10.1016/j.polar.2012.03.002.

World Meteorological Organization, 1989. WMO Sea Ice Nomenclature. Technical Report. World Meteorological Organization. Supplement No. 5, WMO - No. 259. Tp. 145.

Yulmetov, R., Løset, S., Eik, K., 2013. Analysis of drift of sea ice and icebergs in the greenland sea, in: POAC'13, Espoo, Finland. 